\title{
Open Access and ACM
}

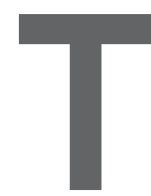

HE BUDAPEST OPEN ACCESS Initiative was issued on Feb. 14, 2002. It argued that "An old tradition and a new technology have converged to make possible an unprecedented public good. ... The public good they make possible is the worldwide electronic distribution of the peer-reviewed journal literature and completely free and unrestricted access to it." I was immediately captivated by the intellectual elegance of the open access proposition, which aims at removing barriers to scholarly knowledge. In 2005, together with colleagues, I launched a new open access journal, Logical Methods in Computer Science (LMCS), ${ }^{\mathrm{a}}$ which to this very day is free to both readers and authors.

But it did not take long for me to realize there is a problem with the business model of "free to both readers and authors"; that is, there are expenses involved in publishing, but "free" means that there is no income! LMCS is run on a shoestring budget, but this model is not scalable. When I became EiC of Communications in 2008, I realized how expensive publishing is. According to the latest ACM Annual Report, b ACM's total publication expenses in fiscal year 2016 were close to US\$11M! Furthermore, ACM's publication revenues were close to US\$21M. The surplus of US\$10M helps fund numerous ACM activities-in education, professional development, public policy, and more. Clearly, ACM's publication business model must be consistent with these realities.

In the standard business model for open access publications, authors of published articles are required to pay article-process charges (APCs), which range from hundreds of dollars to thou-

\footnotetext{
a https://lmcs/episciences.org/
}

b https://goo.gl/fHeZXs sands of dollars. The fact that the monetary transaction of publishing is between the publishers and the authors rather than between publishers and institutions gave rise to the phenomenon of predatory publishing, ${ }^{\mathrm{c}}$ an ugly, unintended consequence of the open access movement.

And yet, in spite of all the complications of open access publishing, the emerging sense of the scientific community is that science publishing should be done under an open access model, which means that articles should be available to readers without charge. ACM is under significant pressure from its membership to move from a subscription-based publishing model to an open access publishing model. Such a transition is exceedingly challenging. A significant drop in ACM's publishing revenue, which would threaten ACM's financial viability, is a risk that must be taken seriously. ACM must engage with its membership to develop and carry out such a transition plan, yet ACM has an obligation to manage such a transition in a way that protects the organization's financial viability and vibrancy.

In his Viewpoint published in this issue- "Push Versus Pull: Flipping the Publishing Business Model" (p. 25)Sheldon Jacobson proposes an alternative business model for open access publishing. In the traditional publishing business model, institutions paid publishers reader-subscription fees to enable their employees and students access to published content. In Jacobson's flipped model, institutions will pay author-subscription fees to enable their employees and students to submit articles for publication. This can be viewed as a variation on the APC-based model, but it takes the authors out of the monetary transaction and recasts it again as

c https://goo.gl/zUqP4r a transaction between institutions and publishers. This offers a solution to the predatory-publishing problem, as institutions are less likely to subscribe to publications of low scholarly quality.

The most significant feature of this proposal is that it involves a significant shifting of publishing costs to researchintensive institutions. The ACM Digital Library (DL) has about 2,500 subscribing institutions, but only about 500 of these institutions publish more than 10 papers annually in the DL, so on the average, author-subscription fees would be about five times higher than reader-subscription fees. But such average-case analysis is misleading. As one would expect, a relatively small number of institutions are "heavy publishers." Jacobson proposes dividing institutions into tiers: Tier I consists of the 70 institutions that publish more than 44 articles per year, while Tier II consists of 850 institutions that publish 6-44 articles per year. His proposal is for Tier I institutions to pay US\$16K for annual author-subscription, and for Tier II institutions to pay US\$10K annually. Other institutions would pay a US\$500 submission fee per article.

As Jacobson points out, the proposed new model may be viewed as unfair to research institutions, but the shifting of publishing costs from readers to authors is inherent in the open access model. Regardless of the weaknesses in Jacobson's proposal, he has opened the door to a substantive discussion about ACM's publishing business model. If we are serious about open access, then we must discuss its underlying business model. Let's get serious about open access!

Follow me on Facebook, Google+, and Twitter.

Moshe Y. Vardi (vardi@cs.rice.edu) is the Karen Ostrum George Distinguished Service Professor in Computational Engineering and Director of the Ken Kennedy Institute for Information Technology at Rice University, Houston, TX, USA. He is the former Editor-in-Chief of Communications.

Copyright held by author 